\title{
Particle swarm optimization tuned unified power flow controller for power oscillation reduction
}

\author{
Ananda M. H. ${ }^{1}$, M. R. Shivakumar ${ }^{2}$ \\ ${ }^{1}$ School of Electrical and Electronics Engineering, REVA University/Research Scholar V.T.U, India \\ ${ }^{2}$ Sri Revana Siddeshwara Institute of Technology, India
}

\begin{tabular}{l} 
Article Info \\
\hline Article history: \\
Received Feb 17, 2021 \\
Revised Jun 30, 2021 \\
Accepted Jul 7, 2021 \\
\hline
\end{tabular}

Keywords:

FACTS

IEEE 9 bus

Particle swarm optimization

PI controller

Power oscillation damping

UPFC

\begin{abstract}
One of the best flexible AC transmission system (FACTS) is unified power flow controller (UPFC). As it gets more benefit from both real and reactive power transfer, it is used in power system for controlling the transmitted power. The UPFC controls the power on the transmission side of the power system. When the real as well as reactive power is set the UPFC tries to follow the command by using the proportional and integral (PI) controller. But in some power systems the PI controllers cannot produce the proper power due to the power oscillations. These oscillations are created due to PI controller properties. In this paper the PI controller is replaced with the particle swarm optimization tuned PI controller (PSO-PI). It minimizes the power oscillations by using the objective function. The MATLAB $2017 \mathrm{~b}$ is used to demonstrate the power transfer curves and the voltages. The IEEE 9 bus system is being used as a reference system.
\end{abstract}

This is an open access article under the $\underline{C C B Y-S A}$ license.

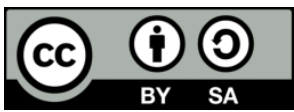

\section{Corresponding Author:}

Ananda M. H

School of Electrical and Electronics Engineering

REVA University

Research Scholar, V.T.U., India

Email: anandmhdvg@gmail.com

\section{INTRODUCTION}

FACTS devices are used for improvement of the power transfer in the power system. In that type UPFC produces both real and reactive power control through the transmission line [1]. There are many types of UPFC compensation like line sending end/ receiving end and mid-point compensations [2]. These devices are used to damp the torque oscillations in the generator a new control is introduced in [3]. Then the voltage stability is done by [4] with radial basis neural network. With same solution reducing the inputs used are used in [5]. As well as the researches to improve the artificial intelligence are also done like direct adaptive network for training it with backpropagation is carried out in [6] and with feed forward neural network [7], [8] are carried out. And in the power system the improvement in transient stability by using the neural network is proposed in [9]. An automatic regulation of the reactive power in a hybrid power system has also been proposed in [10]. The digital signal peripheral interface controller (DSPIC) processor is used for reactive power compensation is depicted in [11] and it is implemented with neural network. Reactive power control with ANN in hybrid power grid is discussed in [12] and based on fuzzy is discussed in [13]. The fault location identification is done with ANN in [14]. There are many researches available in UPFC [15]-[24]. The multiverse optimization is presented in [25] for power sytem oscillation stability. In this paper the PI is tuned to minimize the steady state error of the power in the UPFC control is implemented. This reduces the oscillations with in the power system as the settling time is reduced. 


\section{UPFC MODELING}

The UPFC consist of two converters, which is shown in Figure 1. One is connected in parallel and another one is connected in series to the bus system. So, it can able to handle the real and reactive power in decoupled way by using the control techniques shown in Figure 2. The converter is connected using the series and parallel connected isolated transformers.

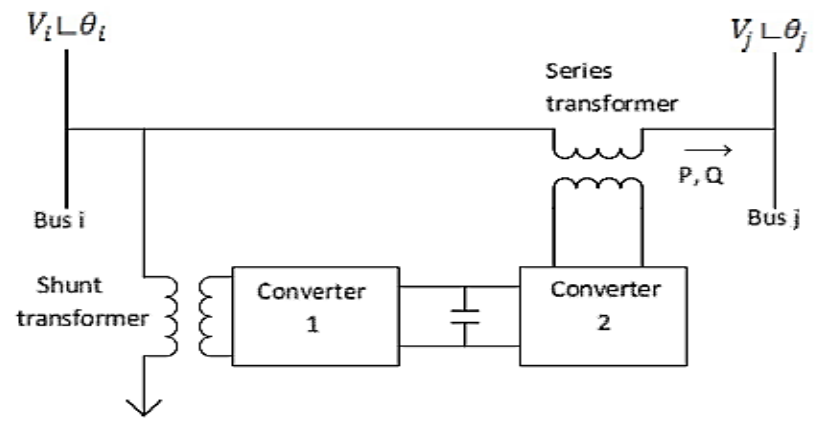

Figure 1. UPFC model

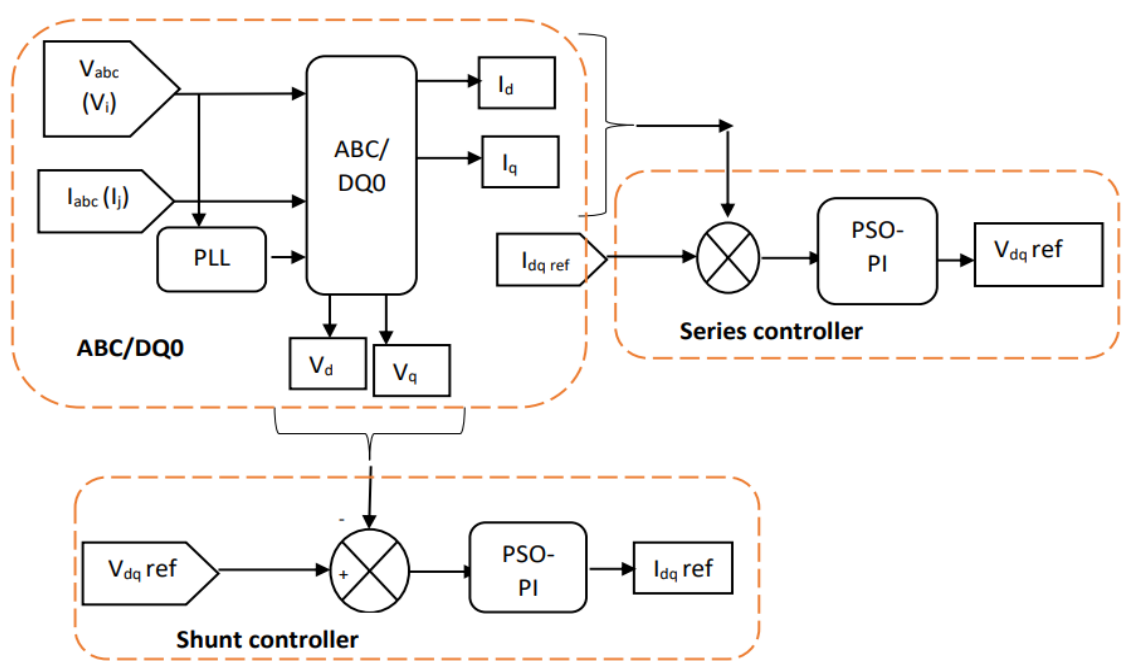

Figure 2. UPFC controller with PSO-PI

In control techniques the control is divided by three. They are $\mathrm{ABC}$ to $\mathrm{DQ} 0$ conversion, series controller and shunt controller. The $\mathrm{ABC}$ to $\mathrm{DQ} 0$ transformation is used for converting decoupling the real and reactive component from the $\mathrm{ABC}$. The series controller compares the Idqref with the measured Idqmeasured. This compared error is given to PI controller or as proposed PSO-PI controller. It is converted to Vdqref. Then shunt controller takes the action and it compares this voltage with reference voltage then it converts it as current. So, series and shunt converters are controlling the voltage and current respectively. Here the PSO-PI is the proposed converter which work optimum compared to PI controller.

\section{OBJECTIVE FUNCTION}

Minimization of Settling time of real power,

$\sum_{i=1}^{n} T S$

With respect to constraints,

$K p \min \leq K p \leq K p \max$ 
where $\mathrm{Ts}$ is the settling time, $\mathrm{Kp}$ min and $\mathrm{Kp}$ max are indeed the minimum and the maximum proportional gains, while $\mathrm{Ki}$ min and $\mathrm{Ki}$ max are also the minimum and maximum Integral gains procured by expertise while using a PI controller.

Particle swarm optimization technique is based on the swarm's food-seeking behaviour [26]. The large group of birds or fishes (particle) actively looking for food and the best particle sharing its position to its neighbourhood particle (whole populace is considered as neighbourhood particle) and the data is shared to whole swarm with best area in the pursuit space. Here, food is the goal work, the particles are the populace and swarm are the absolute populace in each emphasis. As PSO depends on the conduct of the food search in a gathering of fish or bees or birds. The scheme of the algorithm as flow chart is given as Figure 3.

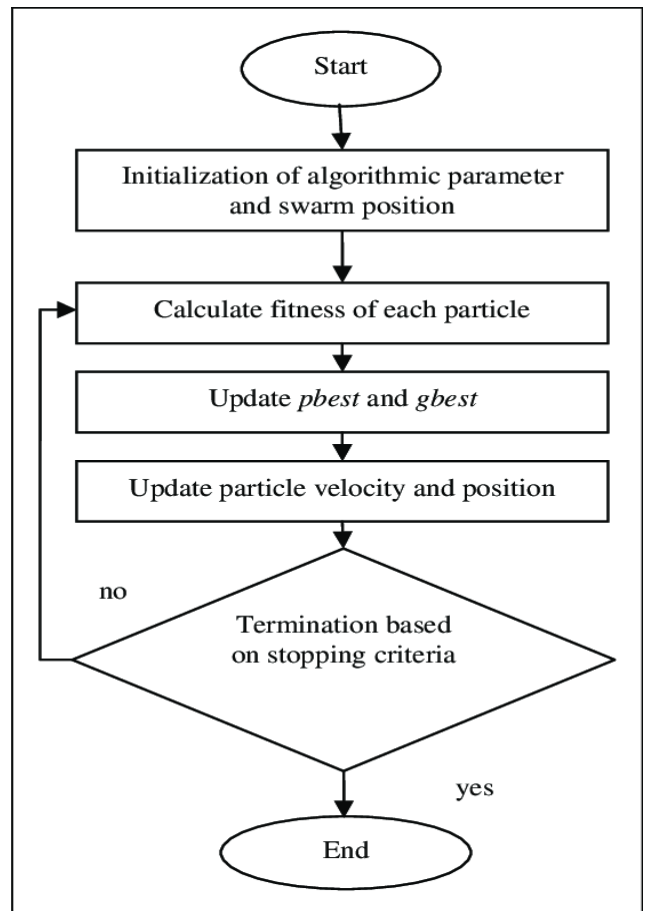

Figure 3. Flow chart of PSO algorithm used for PI controller

\section{RESULTS AND DISCUSSIONS}

The Figure 4 is the proposed standard IEEE 9 bus system for test power system problem. The IEEE 9 bus system is connected with UPFC device. The UPFC is connected at the bus number 4 . The series converter is connected in series with the transmission line between bus 4 to bus 6 . The controls for both the converter is implemented as shown in the Figure 2.

The setpoint power is given as $0.75 \mathrm{pu}$. of real power for UPFC. It is increased to $0.8 \mathrm{pu}$ at 5.5 secs. The total run time is $10 \mathrm{secs}$. The reactive power reference taken is 0.3 pu. The comparative results of the PI controller and PSO-PI are presented in the Table 1 . The PI controller takes only $2.2539 \mathrm{e}-5$ secs to rise. And the PSO-PI takes only $2.245 \mathrm{e}-5$ secs. According to the objective set the settling time is 0.9806 secs for PI controller but using PSO-PI it takes only 0.8723 secs. The other parameters are as tabulated in the Table 1, and it is evident that PSO-PI performance is better. The Figure 5, depicts the Power curves using PI controller in UPFC system. The Figure 6, depicts the Power curves using PSO-PI controller in UPFC device. Figure 7, shows the Comparison of PI and PSO-PI controller in IEEE 9 bus system placed with UPFC. The set point is reached in the output as expected. 


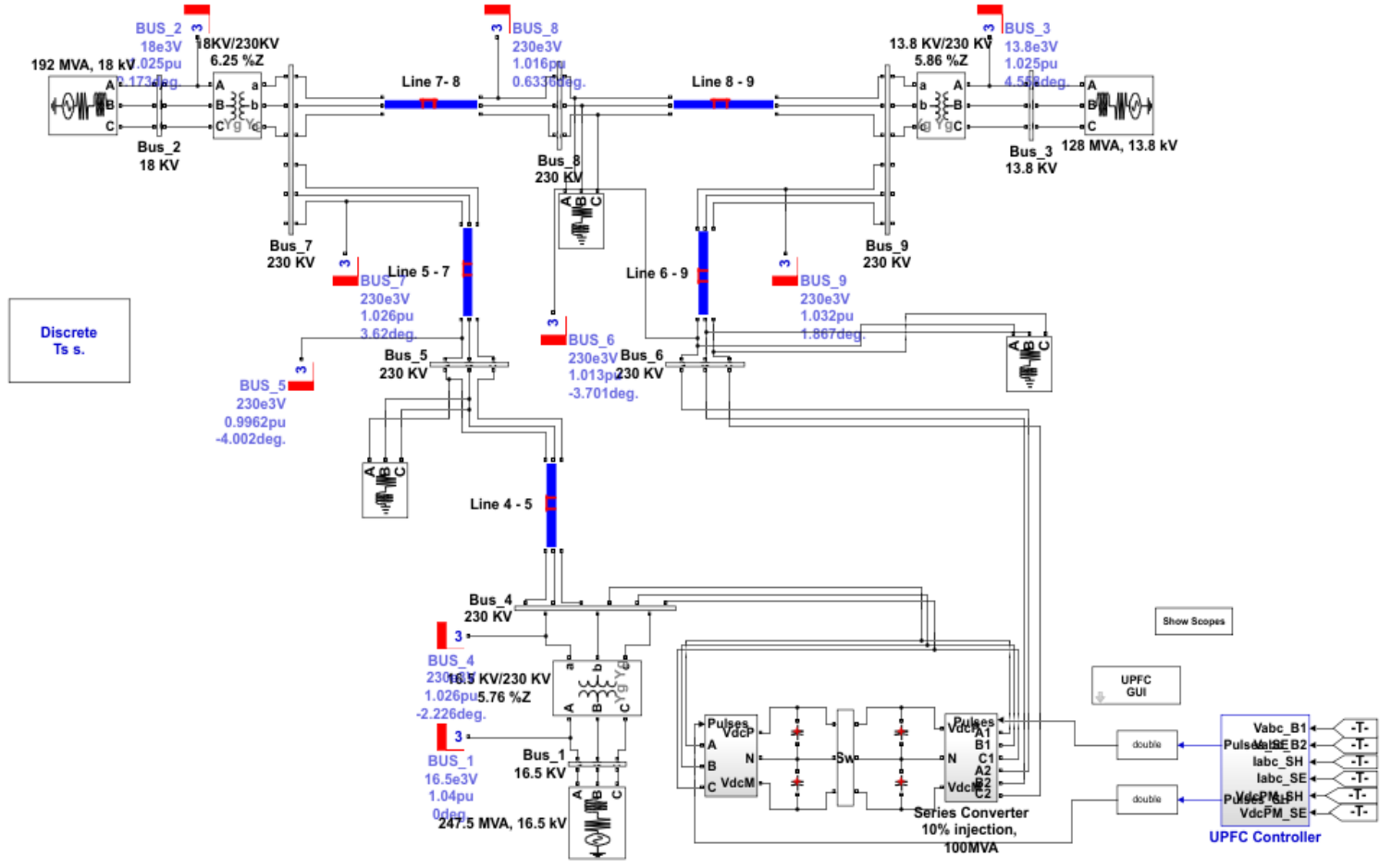

Figure 4. Proposed block diagram (IEEE-9 bus system)

Table 1. Comparison of methods

\begin{tabular}{lcc}
\hline \multicolumn{1}{c}{ Parameter } & PI & PSO-PI \\
\hline Rise Time (sec) & $2.2539 \mathrm{e}-05$ & $2.2450 \mathrm{e}-05$ \\
Settling Time (sec) & 0.9806 & 0.8723 \\
Settling Min\% & 0.0763 & 0.0765 \\
Settling Max \% & 0.0763 & 0.8549 \\
Peak (MW) & 8.6979 & 8.6979 \\
Peak Time (sec) & 0 & 0.2938 \\
\hline
\end{tabular}
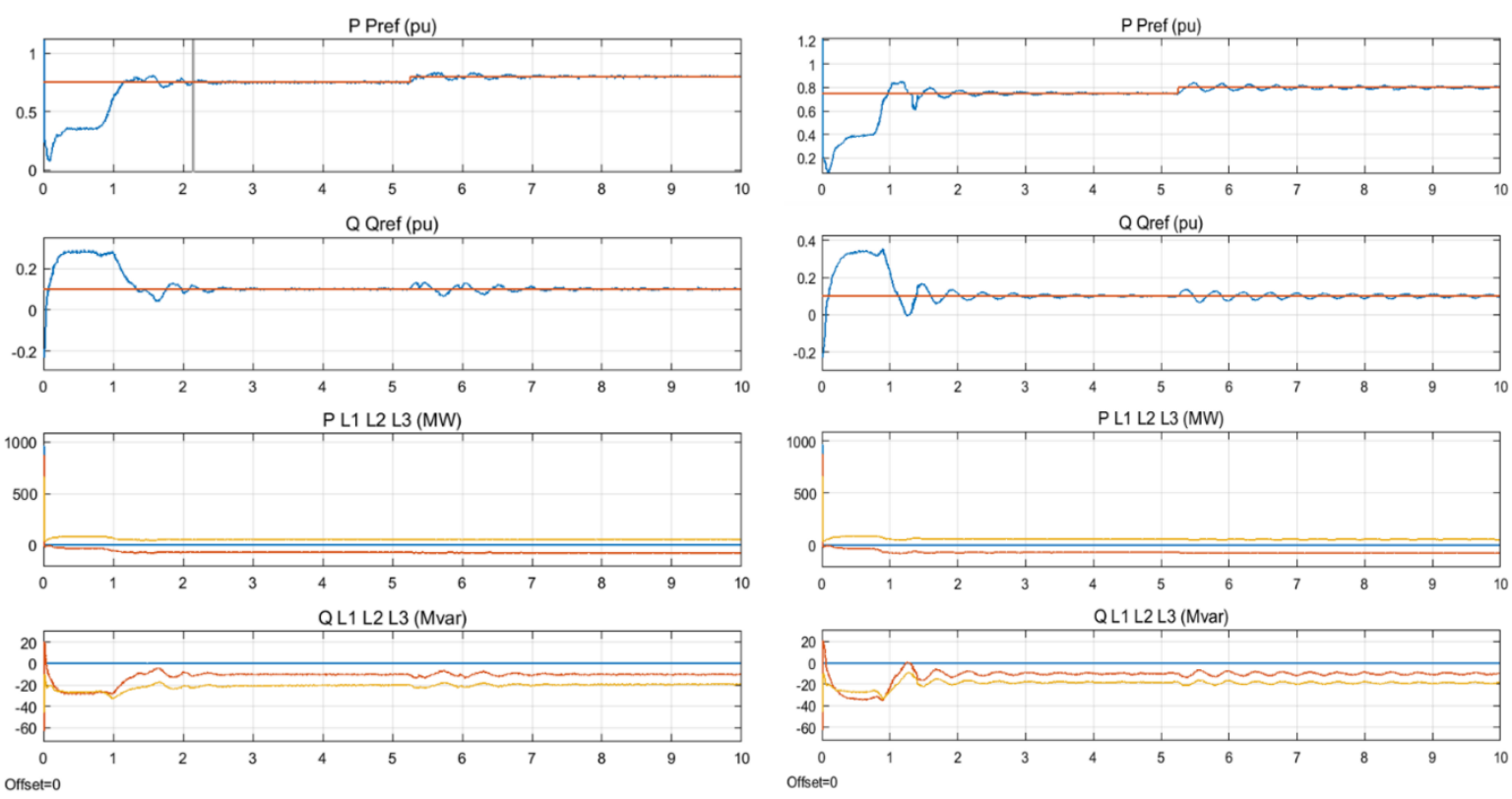

Figure 5. Power curves of PI controller in IEEE-9 bus system
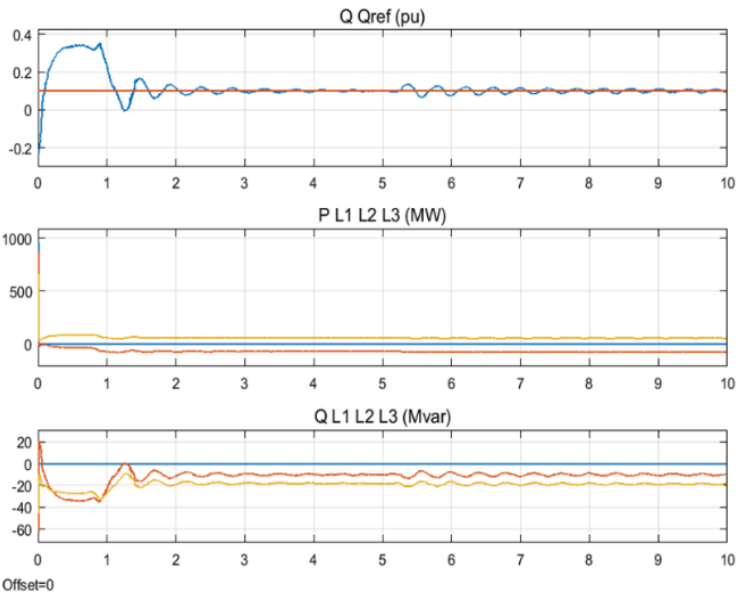

Figure 6. Power curves of PSO-PI controller in UPFC in IEEE 9 bus system 


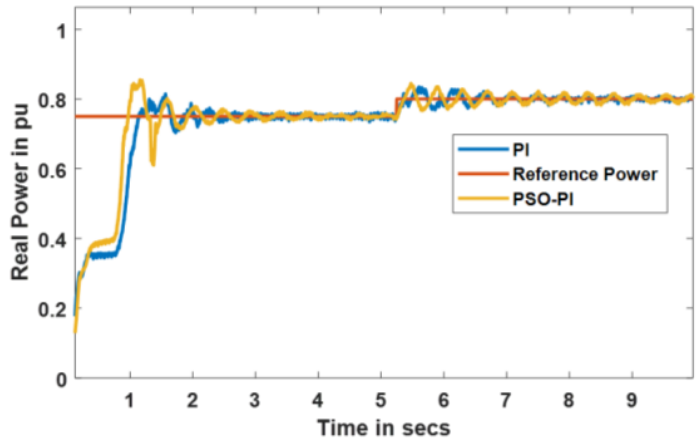

Figure 7. Comparison of PI and PSO-PI controller in IEEE 9 bus system placed with UPFC

\section{CONCLUSION}

The UPFC is placed in dynamic IEEE 9 simulation model. The settling time is minimized by using the PSO algorithm. The comparative analysis of PI and PSO-PI control in UPFC is implemented in this paper. The settling time is minimized in PSO-PI controller. IEEE 9 bus system shows the test results and the time data are tabulated. The particle swarm optimization tuned PI controller (PSO-PI) helps to reduce the power oscillations much better and faster.

\section{REFERENCES}

[1] N. G. Hingorani and L. Gyugyi, Understanding FACTS Concepts and Technology of Flexible AC Transmission system, USA: Wiley-IEEE Press, 2000, pp. 452.

[2] K. R. Padiyar, FACTS Controlling in power Transmission system and distribution, Anshan, United Kingdom, 2008.

[3] K. R. Padiyar and R. K. Varma, "Damping torque analysis of static VAR system controllers," IEEE Transactions on Power Systems, vol. 6, no. 2, pp. 458-465, May 1991, doi: 10.1109/59.76687.

[4] S. Hashemi and M. R. Aghamohammadi, "Wavelet based feature extraction of voltage profile for online voltage stability assessment using RBF neural network," International journal of Electrical power and energy system, vol. 49, pp.86-94, Jul.2013, doi: 10.1016/j.ijepes.2012.12.019.

[5] D. Devraj and J. P. Roselyn, "On line voltage stability assessment using radial basis function network model with reduced input features," International journal of power and energy system, vol. 33, no. 9, pp. 1550-1555, 2011, doi: 10.1016/j.ijepes.2011.06.008.

[6] M. Riedmiller and H. Braun, "A direct adaptive method for faster backpropagation learning: the RPROP algorithm," IEEE International Conference on Neural Networks, San Francisco, CA, USA, vol. 1, 1993, pp. 586-591, doi: 10.1109/ICNN.1993.298623.

[7] Bansal R. C, "Automatic reactive power control of autonomous hybrid power system," PhD Thesis, Center for Energy Studies, Indian Institute of Technology Delhi, India, 2002

[8] R. C. Bansal, T. S. Bhatti, and V. Kumar, "Reactive power control of autonomous wind-diesel hybrid power systems using ANN," International Power Engineering Conference (IPEC 2007), Singapore, 2007, pp. 982-987.

[9] R. A. Jayabarathi and N. B. Devarajan, "ANN Based DSPIC Controller for Reactive Power Compensation," American Journal of Applied Sciences, vol. 4, no. 7, pp. 508-515, 2007, doi: 10.3844/ajassp.2007.508.515.

[10] A. Karami, "Power system transient stability margin estimation using neural networks," International Journal of Electrical Power \& Energy Systems, vol. 33, no. 4, pp. 983-991, May 2011, doi: 10.1016/j.ijepes.2011.01.012.

[11] M. T. Hagan and M. B. Menhaj, "Training feedforward networks with the Marquardt algorithm," IEEE Transactions on Neural Networks, vol. 5, no. 6, pp. 989-993, Nov. 1994, doi: 10.1109/72.329697.

[12] Jurado, Francisco and Saenz, José., "Neuro-fuzzy control for autonomous wind-diesel systems using biomass," Renewable Energy, vol. 27, no. 1, pp 39-56, Sep.2002, doi: 10.1016/S0960-1481(01)00170-7.

[13] A. P. Alves da Silva, A. H. F. Insfran, P. M. da Silveira, and G. Lambert-Torres, "Neural networks for fault location in substations," IEEE Transactions on Power Delivery, vol. 11, no. 1, pp. 234-239, Jan. 1996, doi: 10.1109/61.484021.

[14] S. A. Kiranmai, M. Manjula, and V. R. S. Sarma, "Mitigation of Various Power Quality Problems Using Unified Series Shunt Compensator in PSCAD/EMTDC," 16th National Power Systems Conference, vol. 6, no. 11, pp. 127144, 15th-17th Dec. 2010.

[15] V. Mathad, F. R. Basanagouda, and S. H. Jangamshetti, "Voltage Control and Power System Stability Enhancement using UPFC," International Conference on Renewable Energies and Power Quality (ICREPQ'14), vol. 1, no. 12, pp. 871-875, Apr. 2014

[16] Qing Yu, L. Norum, T. Undeland, and S. Round, "Investigation of dynamic controllers for a unified power flow controller," Proceedings of the 1996 IEEE IECON. 22nd International Conference on Industrial Electronics, Control, and Instrumentation, Taipei, Taiwan, 1996, pp. 1764-1769 vol.3, doi: 10.1109/IECON.1996.570729. 
[17] L. Gyugyi, C. D. Schauder, S. L. Williams, T. R. Rietman, D. R. Torgerson, and A. Edris, "The unified power flow controller: a new approach to power transmission control," IEEE Transactions on Power Delivery, vol. 10, no. 2, pp. 1085-1097, April 1995, doi: 10.1109/61.400878.

[18] M. Noroozian, L. Angquist, M. Ghandhari, and G. Andersson, "Use of UPFC for optimal power flow control," IEEE Transactions on Power Delivery, vol. 12, no. 4, pp. 1629-1634, Oct. 1997, doi: 10.1109/61.634183.

[19] A. Rai, "Enhancement of Voltage Stability \& reactive Power Control of Distribution System Using Facts Devices," International Journal of Scientific Research Engineering \& Technology, vol. 1, no. 9, pp. 001-005, Dec. 2012.

[20] S. Vaibhav Kale, R. P.Prashant, and R. Khatri, "Unified Power Flow Controller for Power Quality Improvement," International Journal of Emerging Science and Engineering (IJESE), vol. 1, no. 10, pp. 1-4, Aug. 2013.

[21] K. Ravichandrudu, P. R. Rani, P. Y. Babu, and G. V. P. Anjaneyulu, "Comparison of Simulation Results of D-Facts \& UPFC Used for Power Quality Improvement," International Journal of Scientific and Research Publications, vol. 3, no. 9, pp. 1-5, Sept. 2013.

[22] G. Kannayeram, N. B. Prakash, R. Muniraj, and T. Sivakumar, "Optimal Tuning of UPFC Damping Controller Using Single and Multi-Objective Evolutionary Algorithms," International Journal of Scientific \& Technology Research, vol. 8, no. 10, pp. 3031-3037, Oct 2019.

[23] S. Hocine and L. Djamel, "Optimal number and location of UPFC devices to enhence voltage profile and minimizing losses in electrical power systems," International Journal of Electrical and Computer Engineering (IJECE), vol. 9, no. 5, pp. 3981-3992, Oct 2019, doi: 10.11591/ijece.v9i5.pp3981-3992.

[24] Ananda M. H. and M. R. Shivakumar, "Dynamic power oscillation reduction using PSOA-PI in UPFC," International Journal of Innovative Technology and Exploring Engineering, vol. 9, no. 2, Dec. 2019, doi: 10.35940/ijitee.B6809.129219.

[25] R. Devarapalli and B. Bhattacharyya, "Power and energy system oscillation damping using multi-verse optimization," SN Appl. Sci., vol. 3, no.3, p. 383, 2021, doi: 10.1007/s42452-021-04349-2.

[26] J. Kennedy and R. Eberhart, "Particle swarm optimization," in Proc. 1995 IEEE Int. Conf. Neural Networks, vol. 4, pp. 1942-1948, doi: 10.1109/ICNN.1995.488968.

\section{BIOGRAPHIES OF AUTHORS}

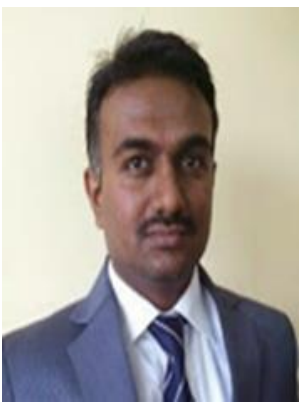

Ananda M. H, Assistant Professor, School of Electrical and Electronics Engineering, REVA University. He holds his B.E in Electrical \& Electronics Engineering and M.Tech in Power Systems \& Power Electronics. His employment experience includes 6 years of industry experience from ABB Ltd., DM-Power Electronics and 8 years of teaching experience. He is Member of IAENG (International Association of Engineers) and Member of IEI (Institution of Engineers India). His special fields of interest included FACTS devices and their application to the power system, FOCS, Smart Grid, Micro Grid, Grid integration of renewable energy sources.

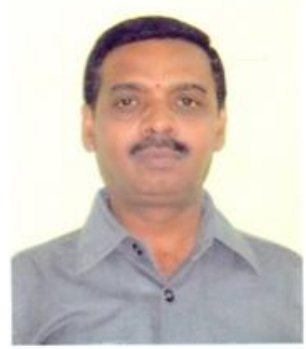

Dr. M R Shivakumar, Professor and Principal, Sri Revana Siddeshwara Institute of Technology, Bangalore, is an Electrical power Engineering graduate from University of Mysore. Post graduate from Bangalore University and also a Ph.D holder in Electrical Engineering (Power Systems) from the same university. He has more than Three decades of teaching experience and guided the students for their Post graduate as well as doctorate degrees. He is a life member of The Indian Society for Technical Education, A Fellow of The Institution of Engineers (India), member of Institution of Engineering and Technology MIET (UK). His field of interest includes power system stability, FACTS controllers, and power electronics applications. 